\title{
POTENCIAL DO FARELO DE ARROZ PARA UTILIZAÇÃO EM BIOPROCESSOS
}

CHAUD, Luciana Cristina Silveira ${ }^{1}$

ARRUDA, Priscila Vaz ${ }^{1}$

FELIPE, Maria das Graças de Almeida ${ }^{1}$

Recebido em: 2009-06-22

Aprovado em: 2009-09-15

ISSUE DOI: $10.3738 / 1982.2278 .268$

RESUMO: A busca por matérias primas renováveis e de baixo custo para a obtenção de diferentes insumos é crescente nos últimos tempos, principalmente devido ao fato de possibilitar a redução de custo de produtos alimentícios com alto valor nutritivo. O farelo de arroz com sua riqueza em nutrientes, principalmente como fonte de vitaminas e minerais é um subproduto da agroindústria brasileira com potencial para ser aproveitado na formulação de alimentos. Entretanto, o aproveitamento biotecnológico do farelo de arroz abre perspectivas econômicas de maior valor agregado para sua utilização em diferentes segmentos industriais. Neste trabalho são apresentadas considerações sobre as características e aplicações do farelo de arroz, bem como resultados de pesquisas sobre a sua utilização na suplementação de meios microbiológicos.

Palavras-chave: Farelo de arroz. Agroindústria. Subproduto. Bioprocessos.

SUMMARY: The search for renewable and low cost raw materials in order to obtain distinct inputs has been increasing, mainly due possibilities of reducing the cost of foods with high nutritious value. Rice bran richness in nutrients, mainly as a source of vitamins and minerals, is a Brazilian agro industrial by-product with potential to be used in food composition. However, the biotechnological use of said rice bran opens economical perspectives of greater collected value due to its use in several different industrial segments. The following work presents comments on the characteristics and applications of rice bran as well as researches results about its uses in the supplementation of microbiological media.

Keywords: Rice bran. Agro industrial. By-product. Bioprocesses.

\section{INTRODUÇÃO}

\section{Farelo de arroz: subproduto do beneficiamento do arroz}

O arroz é considerado o cultivo alimentar de maior importância para muitos países em desenvolvimento e como alimento básico para cerca de 2,4 bilhões de pessoas no mundo, atinge na Ásia, uma produção e consumo da ordem de 90\% (EMBRAPA, 2004). Segundo estudo realizado pela FIESP com o apoio do Ministério da Agricultura, o Brasil se destaca como o maior produtor fora do continente asiático e está entre os dez principais produtores mundiais de arroz, o

\footnotetext{
${ }^{1}$ Departamento de Biotecnologia, Escola de Engenharia de Lorena - USP

* Autor para correspondência: Estrada Municipal do Campinho s/n, CEP 12602-810, Lorena - SP

Fone: (12) 3159-5046 - Fax: (12) 3153-3133 e-mail: lu_chaud@debiq.eel.usp.br
} 
que representa $1,8 \%$ do total mundial produzido, ocupando ainda a nona posição na lista de países consumidores (ARROZ BRASILEIRO, 2008). Segundo o IBGE, está prevista para 2008 uma produção de 12 milhões de toneladas de grãos de arroz em casca, crescimento estimado de 8,5\% em relação à safra de 2007, que foi de 11 milhões de toneladas deste grão (AGÊNCIA BRASIL, 2008). A distribuição nacional da produção de arroz pode ser vista na Figura 1, na qual se destaca o estado do Rio Grande do Sul, por ser este o responsável por mais de 50\% desta produção, o que correspondeu em 2005, cerca de cinco milhões de toneladas (representando 3,1\% do PIB) e R\$ 175 milhões em ICMS, além dos 250 mil empregos naquele Estado, colocando-o como o estabilizador da safra nacional (EMBRAPA, 2005).

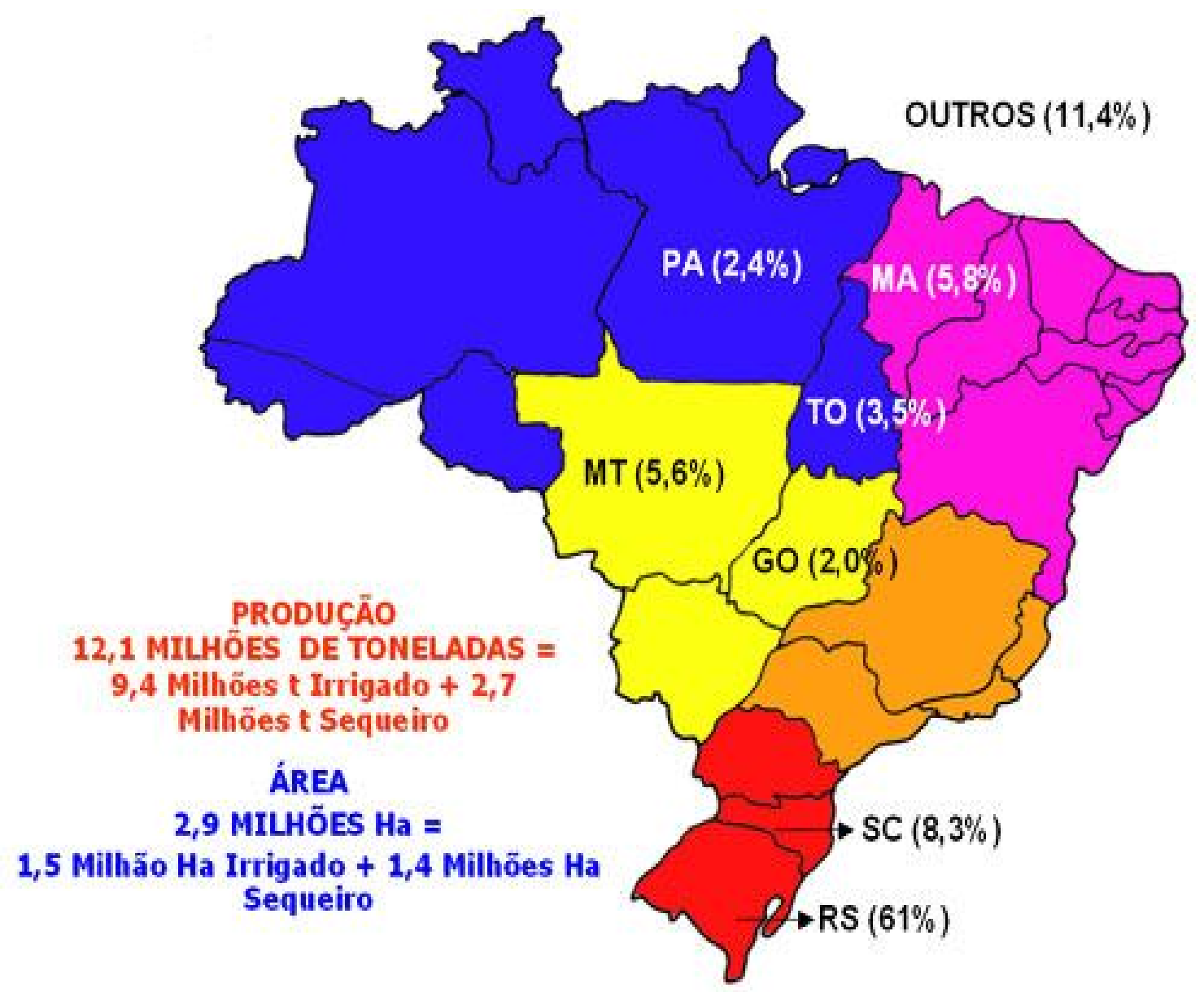

FIGURA 1 - Participação (\%) dos principais estados produtores de arroz (Brasil 2007) (EMBRAPA, 2008).

No processo de beneficiamento do arroz, o farelo de arroz se destaca como importante subproduto, o qual segundo o Instituto Rio-grandense do Arroz vem sendo subaproveitado no montante de mais de um milhão de toneladas/ ano (IRGA, 2008). Sua obtenção é a partir do processo de beneficiamento do arroz, mais especificamente na etapa de brunição, onde o arroz já

Nucleus, v.6, n.2, out. 2009 
descascado, integral, é lixado por máquinas compostas por pedras abrasivas que retiram o farelo, o qual é composto pelo germe e película (Fig. 2) e separam o arroz branco, que após passar pelo processo de polimento se torna o principal componente da alimentação de milhões de brasileiros (EMBRAPA, 2004).
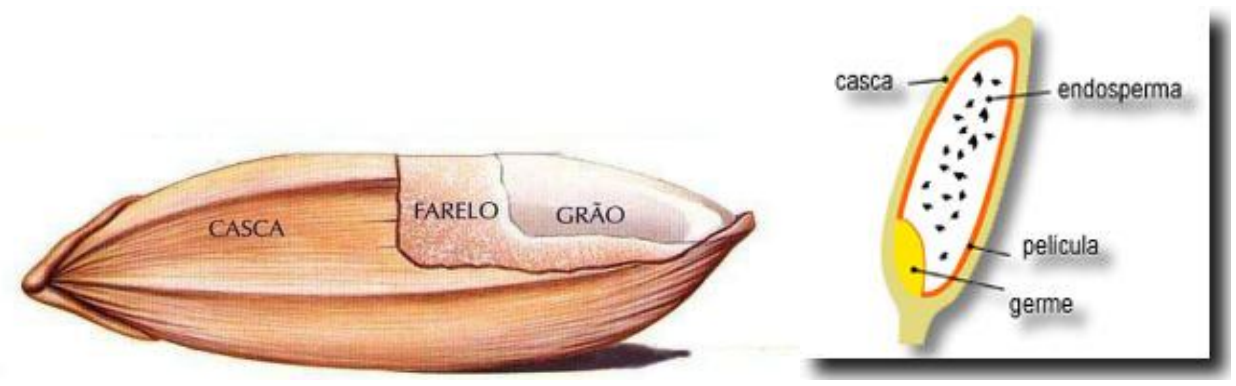

FIGURA 2 - Estrutura do grão de arroz (JOSAPAR, 2008).

O alto teor de gordura presente no arroz, originário principalmente do germe, é o seu principal elemento econômico. Uma vez processado, o farelo poderá produzir até $15 \%$ de óleo cru comestível, além de outros produtos para a indústria cosmética e farmacêutica. O óleo de arroz possui ótimas qualidades nutricionais, sendo formado principalmente por triglicerídeos, com pequenas quantidades de fosfolipídios, glicolipídios e graxas (UFRGS, 2004).

Dado ao elevado valor nutricional do farelo de arroz, várias pesquisas têm sido conduzidas, a fim de avaliar seu potencial para alimentação humana. Porém, a rápida deterioração ocasiona problemas de armazenagem, que, segundo pesquisas realizadas pela Embrapa (2006), poderiam ser atenuados com a adoção de modelos de estabilização térmica do farelo (com calor seco ou microondas) a fim de classificá-lo para o consumo humano.

\section{DESENVOLVIMENTO}

\section{Composição do farelo de arroz}

O farelo representa cerca de 5-8\% do total do grão de arroz, é umas das partes mais nutritivas do grão, fonte de proteínas, fibras dietéticas, compostos funcionais como o orizanol e tocotrienos, além de lipídeos (JULIANO,1994; ORTHOEFER, 1996; McCASKILL; ZHANG, 1999). A sua composição apresentada na Tabela 1, mostra a sua riqueza em nutrientes, tanto na forma integral quanto desengordurada, em comparação a outros subprodutos do beneficiamento do arroz. 
TABELA 1 - Composição química e valores de energia de subprodutos do beneficiamento do arroz (adaptado de LIMA, 2007).

\begin{tabular}{|c|c|c|c|c|c|c|c|}
\hline & $\begin{array}{l}\text { Quirera de } \\
\text { arroz fina }\end{array}$ & $\begin{array}{l}\text { Quirera de } \\
\text { arroz média }\end{array}$ & $\begin{array}{l}\text { Quirera de } \\
\text { arroz grossa }\end{array}$ & $\begin{array}{l}\text { Arroz } \\
\text { vermelho }\end{array}$ & $\begin{array}{l}\text { Farelo de } \\
\text { arroz integral }\end{array}$ & $\begin{array}{l}\text { Farelo de } \\
\text { arroz } \\
\text { desengord. } \\
\end{array}$ & $\begin{array}{l}\text { Farelo de } \\
\text { arroz integral } \\
\text { c/ quirera } \\
\end{array}$ \\
\hline $\begin{array}{l}\text { Matéria } \\
\text { seca }(\%)\end{array}$ & 86,68 & 86,20 & 86,32 & 85,80 & 87,24 & 90,68 & 86,14 \\
\hline $\begin{array}{l}\text { Coeficien } \\
\text { te de } \\
\text { digestibil } \\
\text { idade } \\
\text { aparente } \\
\text { da } \\
\text { matéria } \\
\text { seca }(\%)\end{array}$ & 99,04 & 95,84 & 97,66 & 97,39 & 61,52 & 56,93 & 83,82 \\
\hline $\begin{array}{l}\text { Proteína } \\
\text { bruta (\%) }\end{array}$ & 7,71 & 8,04 & 8,72 & 8,61 & 11,54 & 15,33 & 7,40 \\
\hline $\begin{array}{l}\text { Extrato } \\
\text { etéreo } \\
(\%) \\
\end{array}$ & 1,13 & 0,74 & 0,74 & 1,29 & 15,30 & 0,96 & 3,18 \\
\hline $\begin{array}{l}\text { Fibra } \\
\text { bruta }(\%)\end{array}$ & 0,48 & 0,42 & 0,61 & 0,38 & 10,98 & 9,82 & 4,84 \\
\hline $\begin{array}{l}\text { Cinzas } \\
(\%)\end{array}$ & 0,43 & 0,43 & 0,53 & 0,55 & 8,96 & 10,43 & 2,52 \\
\hline $\mathrm{Ca}(\%)$ & 0,01 & 0,01 & 0,01 & 0,01 & 0,03 & 0,11 & 0,03 \\
\hline $\begin{array}{l}\text { P total } \\
(\%)\end{array}$ & 0,21 & 0,15 & 0,12 & 0,11 & 1,87 & 1,93 & 0,34 \\
\hline $\begin{array}{l}\mathrm{Cu}( \\
\mathrm{mg} / \mathrm{kg})\end{array}$ & 1,71 & 1,63 & 2,24 & 2,64 & 4,19 & 20,18 & 2,46 \\
\hline $\begin{array}{l}\mathrm{Fe}( \\
\mathrm{mg} / \mathrm{kg})\end{array}$ & 9,73 & 8,51 & 15,65 & 26,53 & 82,65 & 286,87 & 93,35 \\
\hline $\begin{array}{l}\mathrm{Mn} \\
(\mathrm{mg} / \mathrm{kg})\end{array}$ & 9,31 & 7,95 & 8,58 & 7,93 & 103,46 & ND & 36,58 \\
\hline $\begin{array}{l}\mathrm{Zn} \\
(\mathrm{mg} / \mathrm{kg})\end{array}$ & 16,18 & 15,67 & 17,05 & 18,33 & 53,89 & 73,74 & 35,42 \\
\hline
\end{tabular}

Devido ao fato de ser o farelo de arroz um subproduto industrial, sua composição química depende de fatores associados à variedade e aos aspectos agronômicos, como tipo de solo, clima, qualidade da matéria prima utilizada, bem como do processo de beneficiamento (FREEMAN, 2006). Segundo Domene (1996), o farelo de arroz integral destaca-se como uma boa fonte de vitaminas do complexo B e E, sendo pobre em vitamina A e ausente de vitamina D. Ainda segundo este autor, o nível de proteína bruta do farelo varia entre 10 a 15\%, sendo superior à proteína do trigo e do milho. Com relação à sua composição mineral, este é extremamente rico em fósforo e manganês, além dos níveis de cobre, ferro e zinco superiores aos do milho (CONTE, 2000). De acordo com Freeman (2006), como outros farelos, o de arroz é rico em fósforo e deficiente em cálcio. Segundo Chandi, Sogi (2007), as propriedades funcionais das proteínas concentradas no farelo de arroz, são comparáveis com a caseína e têm bom potencial na indústria alimentícia.

Nucleus, v.6, n.2, out. 2009 
De acordo com Silva, Sanches e Amante (2006), o farelo de arroz contém entre seus nutrientes, aproximadamente 11,5\% de fibras, sendo ainda uma boa fonte de lipídios, podendo conter mais de $20 \%$ do seu peso em óleo (constituído de ácido oléico, linoléico e ésteres do ácido palmítico), o que muitas vezes limita seu uso, uma vez que a gordura é altamente insaturada e oxidável. A parboilização do farelo de arroz foi sugerida por estes autores, como forma de obter sua estabilização e prevenir sua rancidificação hidrolítica. Em outras pesquisas nas quais foram avaliados diferentes tratamentos para a estabilização do farelo de arroz, foi constatado que o tratamento com microondas seguido pelo tratamento em fogão foi a melhor forma de estabilização, além do que, o tratamento térmico somente em fogão, apresentou resultados satisfatórios, mas foi menos eficiente que aquele apresentado pelo tratamento no forno microondas (AGROSOFT BRASIL, 2006), tratamento este já patenteado (ROCHA; MARSAIOLI JÚNIOR; CABRAL, 2004).

O farelo de arroz possui também componentes antioxidantes, entre eles o orizanol e tocoferóis, (IRGA, 2008), como também o ácido ferúlico, que fornece hidrogênio para a neutralização de radicais livres relacionados ao envelhecimento celular (TSUNO RICE FINE CHEMICALS CO/LTD, 2008). De acordo com Qureshi et al. (2002), o farelo possui ainda tocotrienos que são capazes de reduzir os níveis de colesterol em humanos, sendo seu benefício dose-dependente, com a dose de 100mg/dia de TRF (Fração rica em tocotrienos), a mais indicada para o decréscimo do colesterol total em humanos adultos.

Outra característica do farelo de arroz é sua altíssima quantidade de fitinas (forma pela qual os fosfatos são armazenados), variando de 9,5 a 14,5\%. O ácido fítico tem como função mais importante a quelação de metais, motivo pelo qual já foi condenado no passado em função do sequestramento de cálcio. Porém, hoje em dia, em função da dosagem, este ácido já é visto de forma diferente, sendo importante na fixação do ferro, o que resulta em efeitos positivos para a saúde humana. Novos estudos têm enfatizado a importância da ação carcinostática do ácido fítico, além de sua utilização como aditivo alimentar, propiciando a exaltação do sabor de carnes e peixes (IRGA, 2008).

\section{Aplicações do farelo de arroz}

O farelo de arroz é subutilizado em muitos países do mundo, inclusive no Brasil, onde seu principal aproveitamento é na composição de ração animal, para extração do óleo ou como fertilizante orgânico (SILVA; SANCHES; AMANTE, 2006). Segundo a empresa japonesa Tsuno (2008), como fertilizante orgânico ele é produzido a partir da decomposição química do farelo desengordurado e pode ser utilizado para o cultivo de diversos vegetais, frutas, plantas, etc. No 
Japão, esta empresa produz vários derivados de farelo de arroz, inclusive o óleo e recentemente um produto nutracêutico, rico em vitaminas, proteínas, fibras alimentares, ferro, zinco e inositol.

A atividade antioxidante do farelo de arroz, em virtude da apresentação de componentes como $\alpha$-orizanol, esteróis e tocoferol, é uma das características que impulsiona pesquisas para exploração desta capacidade na produção de alimentos. Batista et al.(2004), avaliando a atividade antioxidante de extratos de farelo de arroz com alguns solventes, revelaram o alto potencial antioxidativo do extrato de farelo de arroz obtido com acetona, em comparação ao uso de BHT (Hidroxitolueno butilado) em óleo de girassol. Martinez et al. (2007), trabalhando também com óleo de girassol, submetido à oxidação induzida a $60^{\circ} \mathrm{C}$, compararam a atividade antioxidante do orizanol (presente no extrato de farelo de arroz) com a do BHA (Hidroxianisol butilado) e do BHT (Hidroxitolueno butilado), os quais são antioxidantes sintéticos empregados na indústria de alimentos. Segundo estes pesquisadores o orizanol exerceu atividade antioxidante, sendo que esta não se encontra diretamente relacionada com sua concentração. Assim, a presença de componentes antioxidantes, bem como o teor de proteínas contidas no farelo de arroz, ratificam seu potencial para compor alimentos funcionais ou nutracêuticos, conforme evidenciado por Parrado et al. (2006). Estes autores demonstraram que extratos enzimáticos de farelo de arroz, com alta capacidade antioxidante, induzem a morte de células leucêmicas e assim, podem suplementar dietas para pacientes portadores de alguns tumores com mínimo de efeitos tóxicos.

Segundo Carvalho e Felippe Jr. (2004), dietas com 10\% de hemicelulose proveniente do farelo de arroz, aumentam o número de leucócitos e de linfócitos no sangue periférico de ratos. Ainda revelam que um polissacarídeo derivado do farelo de arroz, possui atividade antitumor contra fibrosarcomas de camundongos, quando administrado por via oral, sendo que in vitro estimula macrófagos, aumenta a produção de interleucina 1 e induz a atividade tumoricida .

Outros estudos têm explorado as qualidades das proteínas do farelo de arroz, que na forma de concentrados, podem ser incorporadas a produtos alimentícios de alto valor agregado. Hamada et al. (1998), através de cromatografia líquida de alta eficiência (HPLC), investigaram peptídeos de proteínas de farelo do arroz, por sua potencial utilização na indústria de alimentos. Estes autores afirmam que o alto valor nutricional e hipoalergênico destas proteínas, podem fazer deste um produto particularmente atrativo no caso de crianças alérgicas ao leite e/ou proteínas de soja. Enquanto Chandi e Sogi (CHANDI; SOGI, 2007), durante pesquisas nas quais foram avaliados diferentes concentrados de farelo de arroz desengordurado, concluíram que as propriedades funcionais dos concentrados de proteínas de farelo de arroz são comparáveis com as da caseína e têm bom potencial na indústria de alimentos. Nestas pesquisas foram empregadas emulsões estáveis sob diferentes condições de pH, além de concentrações de sal e açúcar.

Nucleus, v.6, n.2, out. 2009 
De acordo com a Embrapa (2004), na cartilha “Utilização do farelo de arroz”, este é um subproduto rico em nutrientes e minerais, que se traduz ainda em excelente alimento funcional, ajudando a prevenir algumas doenças crônicas degenerativas, como colesterol alto, alguns tipos de câncer e o diabetes. Entretanto, para a aplicação nutracêutica do farelo de arroz, Balachandran et al. (2008), propõem um processo ecologicamente correto para obtenção de óleo de farelo de alta qualidade que é a utilização de dióxido de carbono supercrítico. Segundo estes autores, o processamento integrado de bio recursos, vem ganhando atenção hoje em virtude do grande volume de subprodutos que são normalmente subutilizados devido à inadequação das tecnologias convencionais.

Levando-se em conta a composição nutricional do farelo de arroz, aliada a um baixo valor comercial, cerca de R\$340,00/Ton. (MERCADO, 2008), este produto foi um dos eleitos para compor multimisturas para distribuição em creches e programas sociais (VIZEU; FEIJÓ; CAMPOS, 2005), mas há controvérsias quanto ao seu emprego decorrente da indisponibilidade de alguns nutrientes e da toxicidade atribuída a outros (SOCIEDADE BRASILEIRA DE PEDIATRIA, 2008).

Como o farelo de arroz é matéria prima abundante e de baixo custo, alguns pesquisadores têm proposto a sua utilização para a produção de biodiesel, visto que os estudos com o objetivo de determinar a estabilidade térmica e oxidativa do produto final, obtido por transesterificação, têm sinalizado com bons resultados (SILVA et al., 2006; SILVA, C.C. et al., 2006). Segundo Dullius, professora da Pontifícia Universidade Católica do Rio Grande do Sul (PUC-RS), devido às características peculiares da matéria prima, os estudos para obtenção do biodiesel a partir do farelo de arroz resultaram em uma parceria entre esta universidade e a Associação dos Arrozeiros de Uruguaiana, visando à ampliação das possibilidades de negócios e valorização do arroz (ARROZ BRASILEIRO, 2007).

\section{Utilização do farelo de arroz em cultivos microbiológicos}

O elevado valor nutritivo do farelo de arroz aliado à sua relativa disponibilidade e baixo custo, propicia o interesse nas pesquisas biotecnológicas, como tem sido evidenciado em diversos trabalhos nos quais este subproduto foi aproveitado como suplemento na composição de meios de cultivo para diferentes microrganismos, com evidência para os trabalhos que enfocam a produção de xilitol, um açúcar álcool de várias aplicações terapêuticas (FELIPE, 2004).

A suplementação do hidrolisado hemicelulósico de bagaço de cana-de-açúcar com nutrientes como o farelo de arroz, tem sido amplamente empregada em diversos trabalhos, como a sua utilização para a formulação de meios de cultivo para a produção de xilitol por Candida 
guilliermondii (SILVA, 2001). Segundo este autor, a produtividade de xilitol durante fermentação em batelada utilizando $C$. guilliermondii foi favorecida quando o preparo do farelo de arroz foi feito em separado do hidrolisado, ou seja, na forma de um extrato de farelo de arroz. Nestas condições, o preparo do farelo foi feito a partir de uma solução de farelo de arroz na concentração de $200 \mathrm{~g} / \mathrm{L}$ autoclavada a $111^{\circ} \mathrm{C}$ por 15 minutos, seguido de centrifugação asséptica a $2000 \mathrm{xg}$, para o aproveitamento do sobrenadante e descarte do precipitado formado. Nestas condições de preparo, Rodrigues et al. (2001), encontraram que a produção de xilitol por C. guilliermondii cultivada em hidrolisado hemicelulósico de bagaço de cana, foi favorecida quando o hidrolisado foi suplementado com $5 \mathrm{~g} / \mathrm{L}$ de extrato de farelo de arroz juntamente com outros nutrientes. Posteriormente, foi também constatado que além do favorecimento da produção de xilitol por $C$. guilliermondii pela suplementação do hidrolisado hemicelulósico de bagaço de cana-de-açúcar com extrato de farelo de arroz $(5 \mathrm{~g} / \mathrm{L})$, este também foi capaz de suprir as exigências de vitaminas fornecidas pela adição de biotina ao meio de fermentação para a produção de xiilitol por $C$. guilliermondii (RODRIGUES et al., 2005). Enquanto, no caso da fermentação de hidrolisado hemicelulósico de bagaço de cana-de-açúcar por processo semi contínuo, utilizando-se inóculo obtido de células de $C$. guilliermondii imobilizadas em alginato de cálcio, concentração maior de farelo foi requerida para favorecimento deste bio processo (CANILHA; CARVALHO; SILVA, 2005).

A fim de identificar a influência de outras variáveis sobre a bioconversão de xilose em xilitol por $C$. guilliermondii cultivada em hidrolisado hemicelulósico de eucalipto, além do farelo de arroz, Canettieri, Silva e Felipe (2001), realizaram pesquisas empregando a metodologia da superfície de resposta, para avaliação do impacto de fatores como o pH, concentração de xilose, farelo de arroz e sulfato de amônio. Estes autores encontraram que a suplementação do meio com 5,0 g/L de farelo de arroz resultou nos máximos valores de rendimento e produtividade volumétrica de xilitol. Nestas condições o seu preparo foi na forma de extrato conforme mencionado por Silva (2001). Estudos semelhantes foram realizados também com esta mesma levedura cultivada em hidrolisado hemicelulósico de palha de trigo (CANILHA; CARVALHO; SILVA, 2005), os quais revelaram que a suplementação deste hidrolisado também com extrato de farelo de arroz na concentração $5 \mathrm{~g} / \mathrm{L}$, além dos demais nutrientes, propiciou o favorecimento da produção de xilitol. A influência da concentração de farelo de arroz foi avaliada também por Bernardi et al. (2006), em pesquisas nas quais se verificou o comportamento das enzimas xilose redutase e xilitol desidrogenase de $C$. guilliermondii, cultivada em hidrolisado hemicelulósico de casca de aveia. Estas enzimas, responsáveis pelos passos iniciais do metabolismo de xilose, tiveram suas atividades favorecidas, juntamente com o crescimento celular, quando a

Nucleus, v.6, n.2, out. 2009 
concentração do extrato de farelo de arroz foi superior (30g/L) àquela empregada para favorecer este bioprocesso quando o hidrolisado foi de bagaço de cana.

Rossi; Monteiro; Machado (2001), utilizaram farelo de arroz juntamente com melaço de cana-de-açúcar, com o intuito de suplementar meio de cultivo contendo como substrato o bagaço de cana para a produção de "semente" de shiitake (Lentinula edodes). Estes autores observaram que as suplementações com 25 a $30 \%$ de farelo de arroz proporcionaram maior estimulação do vigor micelial e aumentaram o valor da biomassa estimada, enquanto a utilização de concentrações maiores prejudicou a velocidade de crescimento. Cogumelos do gênero Pleurotus também tiveram sua eficiência biológica e rendimento avaliados por Santos et al. (2000), que constataram incremento do rendimento de 18 para 23,5\% em termos de peso seco, com a suplementação do substrato palha de bananeira com farelo de arroz $(5 \%$ p/p), o que levou à recomendação de sua utilização em virtude do seu baixo custo.

Muitos pesquisadores têm investigado a possibilidade de utilização de farelo de arroz também como nutriente para formulação de meios para a produção de ácido lático, visando à redução do custo de produção deste ácido (GAO, 2007). Resultados destas pesquisas evidenciaram que a produção do ácido lático quase dobrou com a adição de farelo de arroz ao meio de cultivo da bactéria Lactobacillus amylovorus (ODA, 1997). No caso da bactéria Lactobacillus sp. RKY2, boa produtividade deste ácido também foi obtida com utilização de farelo de arroz hidrolisado com enzimas (YUN, 2004). A utilização de hidrolisado de farelo de arroz desengordurado obtido a partir da prévia sacarificação com amilase e celulase, foi avaliada também para a produção de ácido lático por Lactobacillus delbruekii (TANAKA et al., 2006). Nestas pesquisas foi constatado um rendimento de 78\% na produção deste ácido por esta bactéria. Enquanto Gao et al. (2007), avaliando a utilização de farelo de arroz como fonte nutricional para Lactobacillus rhamnosus, sugerem que seu prévio tratamento por hidrólise ácida, pode ser a solução para a redução do custo do meio de cultivo para a produção de ácido lático. Porém, segundo estes autores a utilização do hidrolisado de farelo prolongou a fase lag de crescimento bacteriano para até 40 horas, observando-se uma redução quando se adicionou junto ao farelo o extrato de levedura em pequena quantidade. Esta combinação resultou em uma produtividade 1,6 vezes maior em relação à fermentação controle, na qual se empregou extrato de levedura.

A suplementação do hidrolisado hemicelulósico de bagaço de cana-de-açúcar com extrato de farelo de arroz foi também avaliada para o cultivo da bactéria Bacillus licheniformis E44 (PALADINO, 2008). Segundo estes autores, o farelo (20 g/L) exerceu influência positiva sobre o crescimento desta bactéria e foi este juntamente com a caseína um dos fatores mais significativos. 
Pesquisas para o incremento da produção de determinadas enzimas tem sido também feitas com a utilização farelo de arroz como suplemento ou o próprio substrato em meios de cultivo, como pode ser constatado em trabalhos para a seleção de linhagens de Rhizopus sp com vistas à produção de protease neutra (SUMANTHA et al., 2006), onde os autores verificaram o favorecimento desta enzima quando o substrato (farelo de arroz) foi suplementado com uma fonte de carbono. Para a produção de xilanases, a hemicelulose do farelo de arroz foi utilizada como substrato e única fonte de carbono para Paenibacillus sp (HARADA, 2008). No caso da amilase, o farelo de arroz presente no meio de cultivo para o fungo Macrophomina phaseolina, foi um bom indutor para a produção desta enzima (FERNANDES et al., 2007).

Alguns estudos buscam ainda empregar microrganismos GRAS (Generally Reconized as Safe) como, por exemplo, o Saccharomyces cerevisiae, para melhorar as propriedades físico químicas e nutricionais do farelo de arroz (FEDDERN; FURLONG; SOARES, 2007). Estes autores observaram aumento no teor de fibras e cinzas após a fermentação do farelo de arroz por esta levedura, com diminuição no conteúdo de carboidratos e metionina disponível, concluindo que estes resultados sugerem a possibilidade de aumento do período de conservação e melhoria da palatabilidade dos farelos. Enquanto Silveira e Furlong (SILVEIRA; FURLONG, 2007) observaram que farelos de arroz e trigo submetidos à fermentação em estado sólido pelos fungos Rhizopus sp. e Aspergillus oryzae tiveram seus teores de aminoácidos totais, aminoácidos digeríveis e metionina disponível, aumentados e maiores aumentos de teores protéicos observados nos farelos fermentados por Rhizopus sp.

\section{CONCLUSÃO}

O farelo de arroz, um subproduto da agroindústria, é bastante rico em nutrientes e tem seu potencial subutilizado em muitos países do mundo. Embora a sua característica de deterioração seja um fator limitante para a sua utilização, várias pesquisas têm sido feitas, com o intuito de garantir a sua estabilização e possibilitar o incremento de seu emprego em diferentes segmentos industriais.

As aplicações do farelo de arroz têm sido cada vez mais surpreendentes e diversificadas, indo desde a utilização em ração animal, suplemento para humanos e produção de fertilizantes, até a composição nutricional de meios de cultura, passando ainda pela produção do óleo e a extração de diversos insumos, como antioxidantes e proteínas para a indústria de alimentos.

No Brasil, a mentalidade que aliava subprodutos agroindustriais à produção de ração para alimentação animal, vem gradativamente sendo substituída, à medida que a comunidade científica se interessa por estes produtos, como nutrientes de baixo custo para a composição de

Nucleus, v.6, n.2, out. 2009 
meios de cultivo em pesquisas biotecnológicas para a produção de produtos de alto valor agregado. Assim, o farelo de arroz desponta para a área científica com a promessa de alcançar grandes índices de importância, a exemplo do que acontece com o arroz no mundo de hoje.

\section{REFERÊNCIAS}

AGÊNCIA BRASIL. Segundo IBGE, produção de arroz crescerá 8,5\% neste ano. 2008. Disponível em: http://www.agenciabrasil.gov.br/noticias/2008/03/03/materia.2008-0303.6634712834/view . Acesso em jul.2008.

AGROSOFT BRASIL. Efeito do tratamento térmico na conservação do farelo de arroz. 2006. Disponível em: http://www.agrosoft.org.br/?q=node/21387 . Acesso em jun./2008.

ARROZ BRASILEIRO. Cultura do arroz é destaque em estudo produzido pela Fiesp. 2008. Disponível em : http://www.arroz.agr.br/site/arrozemfoco/080519.php. Acesso em jun. 2008.

ARROZ BRASILEIRO. Óleo de farelo de arroz também é opção para biodiesel, 2007. Disponível em: http://www.arroz.agr.br/site/arrozemfoco/070521.php . Acesso em jul.2008.

BALACHANDRAN, C. et al. An ecofriendly approach to process rice bran for high quality rice bran oil using supercritical carbon dioxide for nutraceutical applications. Bioresource Technology, v. 99, p. 2905-2912, 2008.

BATISTA, A. et al. Ação antioxidante de extratos de farelo de arroz com diferentes níveis de polaridades. In: CONGRESSO DE CIÊNCIAS FARMACÊUTICAS DE CASCAVEL, 1 e SIMPÓSIO EM CIÊNCIA E TECNOLOGIA DE ALIMENTOS DO MERCOSUL, 1. Resumos... Universidade Estadual do Oeste do Paraná (UNIOESTE), Cascavel, 2004.

BERNARDI, F.P. Avaliação da suplementação do hidrolisado hemicelulósico de casca de aveia com farelo de arroz sobre a atividade das enzimas xilose redutase e xilitol desidrogenase. SEMINÁRIO BRASILEIRO DE TECNOLOGIA ENZIMÁTICA (ENZITEC), 7. Resumos..., p. 163, Caxias do Sul, 2006.

CANETTIERI, E.V.; SILVA, J.B.A.; FELIPE, M.G.A. Aplication of factorial design to the study of xylitol production from Eucalyptus hemicellulosic hydrolysate. Applied Biochemistry and Biotechnology, v. 94, p. 159-168, 2001.

CANILHA, L.; CARVALHO, W.; SILVA, J.B.A. Influence of medium composition on xylitol bioproduction from wheat straw hemicellulosic hydrolysate. World Journal of Microbiology Biotechnology, v. 21, n.(6-7, p. 1087-1093, 2005.

CARVALHO, R.C.; FELIPPE JR. Arroz integral: o farelo de arroz possui atividade antiradical hidroxila, antiradical superóxido e contém em sua composição: SODCu-Zn. Associação

Brasileira de Medicina Complementar, 2004. Disponível em:

http://www.medicinacomplementar.com.br/arroz integral.asp. Acesso em abr.2008.

CARVALHO, W.; CANILHA, L.; SILVA, S.S. Semi-continuous xylitol bioproduction in sugarcane bagasse hydrolysate: effect of nutritional supplementation. Revista Brasileira de Ciências Farmacêuticas, v. 43, p. 47-53, 2007.

CHANDI, G.K. ; SOGI, D.S. Functional properties of rice bran protein concentrates. Journal of Food Engineering, v. 79, n.02, p. 592-597, 2007. 
CONTE, A.J. Valor nutritivo do farelo de arroz integral em rações para frangos de corte, suplementado com fitase e xilanase. 2000, 164f. Tese (Doutorado). Universidade Federal de Lavras.

DOMENE, S.M.A. Estudo do valor nutritivo mineral do farelo de arroz. Utilização do zinco, ferro, cobre e cálcio pelo rato em crescimento. 1996, 104f.. Tese (Doutorado). Universidade de Campinas.

EMBRAPA - EMPRESA BRASILEIRA DE PESQUISA AGROPECUÁRIA. Sistemas de produção. 2004. Disponível em:

http://www.sistemasdeproducao.cnptia.embrapa.br/fonteshtml/arroz . Acesso em jun. 2008.

EMBRAPA - EMPRESA BRASILEIRA DE PESQUISA AGROPECUÁRIA. Utilização do farelo de arroz. 2004. Disponível em:

http://www.cnpaf.embrapa.br/publicacao/folhetos/arroz_farelo.pdf . Acesso em maio 2008.

EMBRAPA - EMPRESA BRASILEIRA DE PESQUISA AGROPECUÁRIA. Cultivo do arroz irrigado no Brasil. 2005. Disponível em:

http://www.sistemasdeproducao.cnptia.embrapa.br/FontesHTML/Arroz/ArrozIrrigadoBrasil .

Acesso em jun. 2008.

EMBRAPA - EMPRESA BRASILEIRA DE PESQUISA AGROPECUÁRIA- Uso do farelo de arroz na alimentação humana. 2006. Disponível em:

http://www.sct.embrapa.br/radio/2006/abordagens/norte/release_16_farelo_arroz. Acesso em jun. 2008.

EMBRAPA- EMPRESA BRASILEIRA DE PESQUISA AGROPECUÁRIA- Arroz e Feijão.

Disponível em:

http://www.cnpaf.embrapa.br/apps/socioeconomia/docs/arroz/produtores_arroz.htm . Acesso em ago. 2008 .

FEDDERN, V.; FURLONG, E.B.; SOARES, L.A.S. Efeitos da fermentação nas propriedades físico-químicas e nutricionais do farelo de arroz. Ciência e tecnologia de Alimentos, v.27, n.4, p.800-804, 2007.

FELIPE, M.G.A. Biotechnological Production of Xylitol from Lignocellulosic Materials. In: SAHA, B.C.; HAYASHI, K. (eds.) Lignocellulose Biodegradation; American Chemical Society, cap. 18, 2004.

FERNANDES, L.P. et al. Produção de amilases pelo fungo Macrophomina phaseolina. Revista Eletrônica de Farmácia, v. 4, n. 1, p. 43-51, 2007.

FREEMAN, D.W. Use of by-product and nontraditional feeds for horses. 2006. Disponível em: http://osuextra.okstate.edu/pdfs/F-3923web.pdf. Acesso em abr. 2008.

GAO, M.T. et al. Utilization of rice bran as nutrient source for fermentative lactic acid production. Bioresource Technology, v. 99, p. 3659-3664, 2007.

HAMADA, J.S. et al. Preparative separation of valu-added peptides from rice bran proteins by high-performance liquid chromatography. Journal of chromatography A, v. 827, p. 319-327, 1998.

HARADA, M.H. et al. Paenibacillus sp. Strain HC1 xylanases responsible for degradation of rice bran hemicellulose. Microbiological Research, v.163, n. 3, p.293-298, 2008.

Nucleus, v.6, n.2, out. 2009 
IRGA - INSTITUTO RIOGRANDENSE DO ARROZ. Farelo de arroz: uma nova visão. 2008. Disponível em: http://www.irga.rs.gov.br/index.php?action. Acesso em 05/2008.

JOSAPAR. Disponível em: http://www.josapar.com.br/ . Acesso em: jul.2008.

JULIANO, O.B. (Ed.). Rice: chemistry and technology. 2nd ed. St. Paul, EUA: The American Association of Cereal chemist's inc., 1994. pp.17-160.

LIMA, G.J.M.M. et al. Composição química e valores de energia de subprodutos do beneficiamento do arroz. 2007. Disponível em:

http://www.cnpsa.embrapa.br/down.php?tipo=artigo\&cod_artigo=102. Acesso em abr. 2008.

MARTINEZ, D.M. et al. Comparação da atividade antioxidante de $\gamma$-orizanol, BHA e BHT em óleo de girassol submetido à oxidação induzida a $60^{\circ} \mathrm{C}$. CIC, 16 e ENCONTRO DE PÓS GRADUÇÃO UFPel , 16. Resumos... Universidade Federal de Pelotas, 2007.

McCASKILL, D.R.; ZHANG, F. Use of rice bran oil in foods. Food Technology, v. 53, n.2, p.50-53, 1999.

MERCADO- CORRETORA DE MERCADORIAS. Cotações do produto farelo de arrozFOB. Disponível em:

http://www.clicmercado.com.br/cotacoes/cotacoes2.asp?IDproduto=24\&FOBCIF=1. Acesso em set. 2008.

ODA, Y.J. et al. Recycling of bakery wastes using an amylolytic lactic acid bactéria. Bioresource Technology, v. 60, p. 101-106, 1997.

ORTHOEFER, F. Rice bran oil: health lipid source. Food Technology, v. 50, n.12, p.62-64, 1996.

PALADINO, F. et al. Influência da suplementação nutricional de hidrolisado hemicelulósico de bagaço de cana-de-açúcar no crescimento de Bacillus licheniformis. V ENCONTRO DE INICIAÇÃO CIENTÍFICA, 5. MOSTRA DE PÓS GRADUAÇÃO, 3 e SEMINÁRIO INTERNO PIBIC- CNPq- FATEA, 2. Resumos... Lorena, 2008.

PARRADO,J. et al. Preparation of a rice bran enzymatic extract with potencial use as functional food. Food Chemistry, v. 98, p. 742-748, 2006.

ROCHA, C..R.; MARSAIOLI JÚNIOR, A.; CABRAL, E.C. dos S. Processo para estabilização dos grãos e do farelo de arroz através de tratamento por microondas. Patente n. PI0203682-7. Campinas: UNICAMP, 2004. Disponível em: http://www.patentesonline.com.br/processo-paraestabilizacao-dos-graos-e-do-farelo-de-arroz-atraves-de-tratamento-319.html . Acesso em: jun. 2008 .

QURESHI, A.A. et al. Dose-dependent suppression of serum sholesterol by tocotrienol-rich fraction $\left(\mathrm{TRF}_{25}\right)$ of rice bran in hypercholesterolemic humans. Atherosclerosis, v.161, p.199-207, 2002.

RODRIGUES, R.C.L.B. et al. Avaliação da suplementação nutricional do hidrolisado de bagaço de cana para a produção de xilitol por Cândida guilliermondii. In: CONGRESSO BRASILEIRO DE MICROBIOLOGIA, 23. Resumos... Santos, 2005.

RODRIGUES, R.C.L.B. et al. The influence of nutrients of sugarcane bagasse hydrolysate for biotechnological xylitol production. In: EUROPEAN CONGRESS ON BIOTECHNOLOGY, 10. p.175, Madrid, 2001. 
ROSSI, H.I.; MONTEIRO, A.C.; MACHADO, J.O. Desenvolvimento micelial de Lentinula edodes como efeito da profundidade e suplementação do substrato. Pesquisa Agropecuária Brasileira, v. 36, n.6, p. 887-891, 2001.

SANTOS, V.M.C.S. et al. Estudo da fração de inoculo e da suplementação da palha de bananeira para produção de Pleurotus sajor- caju. Revista Saúde e Ambiente, v.1, n.1, p.64-67, 2000.

SILVA, C. et al. (2006). Farelo de arroz: alternativa na produção de biodiesel. Disponível em: http://www.cpamn.embrapa.br/agrobioenergia/trabalhos/056.PDF . Acesso em jul. 2008.

SILVA, C.C. et al. Estudo da estabilidade térmica e oxidativa do óleo e do biodiesel derivado do óleo de farelo de arroz. In: CONGRESSO BRASILEIRO DE ANÁLISE TÉRMICA E COLORIMETRIA, 5 - CBRATEC. Resumos... Associação Brasileira de Análise Térmica e Calorimetria, João Pessoa, 2006.

SILVA, D.D.V. Efeito do Ácido Acético na Bioconversão de Xilose em Xilitol por Candida guilliermondii em Hidrolisado de Bagaço de Cana-de-Açúcar. 2001. 73 f. Dissertação ( Mestrado). FAENQUIL/ Departamento de Biotecnologia. Lorena.

SILVA, M.A.; SANCHES, C.; AMANTE, E.R. Prevention of Hydrolytic rancidity in rice bran. Journal of Food Engineering, v.75, v.4, p. 487-491, 2006.

SILVEIRA, C.M.; FURLONG, E.B. Caracterização de compostos nitrogenados presentes em farelos fermentados em estado sólido. Ciência e Tecnologia de Alimentos, v. 27, 4, p.805-811, 2007.

SOCIEDADE BRASILEIRA DE PEDIATRIA. Nutrição infantil: alimentação alternativa:

Posição da Sociedade Brasileira de Pediatria. Disponível em:

http://www.sbp.com.br/show_item2.cfm?id_categoria=24\&id_detalhe=1597\&tipo_detalhe=s.

Acesso em mar. 2008.

SUMANTHA, A. et al. Rice bran as substrate for proteolytic enzyme production. Brasilian Archives of Biology and Technology, v. 49, n.5, p. 843-851, 2006.

SUNO RICE FINE CHEMICALS CO./LTD. Tremendous potencials of rice bran. Disponível em: http://www.tsuno.co.jp/e/04/main.htm . Acesso em jul. 2008.

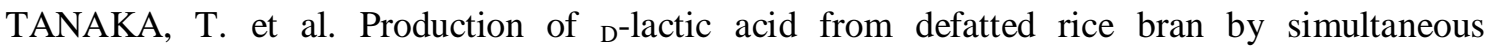
saccharification and fermentation. Bioresource Technology, v. 97, p. 211-217, 2006.

UFRGS (2004)- UNIVERSIDADE FEDERAL DO RIO GRANDE DO SUL-Processamento de alimentos de origem vegetal/ arroz. Disponível em: http://www.ufrgs.br/alimentus/agronom/arroz . Acesso em maio 2008.

VIZEU, V.E.; FEIJÓ, M.B.S.; CAMPOS, R.C. Determinação da composição mineral de diferentes formulações de multimistura. Ciência e Tecnologia de Alimentos, v. 25, n.2, p. 254258, Campinas, 2005.

YUN, J.S. et al. Fermentative production of $\mathrm{DL}^{-}$lactic acid from amylase-treated rice and wheat brans hydrolysate by a novel lactic acid bacterium, Lactobacillus sp. Biotechnology Letters, v. 26, p. 1613-1616, 2004.

Nucleus, v.6, n.2, out. 2009 